\title{
PRECURSORY SEISMICITY PATTERNS
}

\author{
Max Wyss \\ University of Colorado \\ CIRES \\ Boulder, Colorado 80309
}

USGS CONTRACT NO. 14-08-0001-18386

Supported by the EARTHQUAKE HAZARDS REDUCTION PROGRAM

OPEN-FILE NO. 81-890

U.S. Geological Survey

OPEN FILE REPORT

This report was prepared under contract to the U.S. Geological Survey and has not been reviewed for conformity with USGS editorial standards and stratigraphic nomenclature. Opinions and conclusions expressed herein do not necessarily represent those of the USGS. Any use of trade names is for descriptive purposes only and does not imply endorsement by the USGS. 


\section{TABLE OF CONTENTS}
A. BREAKDOWN
в. DISCUSSION

1. Data Acquisition

2. Software and algorithms

3. Uniformity of seismicity catalogues

4. Seismicity quiescence within source volumes of recent large earthquakes

5. Is seismicity quiescence a precursory phenomenon?

6. Model for quiescence

7. Quiescence within seismic gaps

C. ARTICLES PREPARED

D. CONCLUSIONS AND RECOMMENDATIONS

APPENDIX A: Earthquake Hazard in the Hellenic Arc

APPENDIX B: Precursory Seismicity Patterns: Stalking the Mature Seismic Gap (abstract)

APPENDIX C: Consistency of teleseismic reporting since 1963 (abstract) 


\section{A. BREAKDOWN}

The research on seismicity rate fluctuation before large earthquakes as carried out under this contract can be broken down into the following tasks:

1. Data acquisition

2. Development of software and algorithms for data analysis

3. Testing of the seismicity catalogues for homogeneity as a function of space and time.

4. Study of the seismicity patterns within source volumes of recent large earthquakes

5. Examination of the relationship between seismicity rate anomalies and other possible precursors

6. Proposing of a model explaining precursory seismicity rate changes

7. Studies of seismicity patterns within seismic gaps.

8. Long term prediction of large earthquakes.

The most significant progress which has been made in these tasks is summarized in this report. More details of the work is given in the six articles published or submitted for publication with support of this contract (see Chapter C.).

\section{B. DISCUSSION}

\section{Data Acquisition}

For most of our work the NOAA world catalogue of hypocenters was used. In addition hypocenter data from the ISC and local catalogues were used to improve the data base of certain regions studied. For this reason the data acquisition is an ongoing process to some extent. As time goes on we update our data base, and as we start to study new regions we improve the data set for these regions if local catalogue data are available for extended time periods. 
Usually such data expansions are accomplished by transferring the hypocenter data on punched cards for analysis by computer. All of our hypocenter files are stored on disc and tapes.

\section{Software and algorithms}

Codes were developed for the data selection, the quantitative analysis of seismicity patterns by algorithms, and for graphical display of the results. These codes are extensively used in an interactive mode on the DEC 11/70 system provided for CIRES by the USGS. The codes which are used most frequently at the present are those searching for seismicity quiescence in time and space by normal deviate $(z)$-tests.

Two general schemes for applying the normal deviate test to seismicity data are presently in use. The first, termed $A S(t)$, uses a background estimate which expands with time. This approach is most useful in regions with relatively small numbers of events where a longer time period is needed for a confident estimate of the background or normal seismicity rate. $A S(t)$ is difficult to use in regions with complex seismicity rate histories which may include mainshock-aftershock sequences. In these regions the background period used to compare possible anomalies with must be carefully selected for a meaningful application of $A S(t)$.

The observation that many regions experience relatively long periods of constant background seismicity rates allows the application of the second approach, a function termed $z(t)$. This function differs from $A S(t)$ in that a moving time window of constant duration is used for a background estimate. Mainshock-aftershock sequences only affect the background estimate for the duration of the constant length window.

Both of these approaches have been used for anomaly recognition and for testing the temporal and spatial uniqueness of possible anomalies. Both 
approaches are now being incorporated into real-time seismicity rate analysis algorithms.

\section{Uniformity of seismicity catalogues}

The detection of seismicity quiescence (local decrease of seismicity rate for a limited time period) has been at the center of our efforts. Quiescence is said to exist if we can demonstrate that within a given volume of a seismic zone the seismicity rate was constant ( \pm small variance) over a period of time, the background period, after which it dropped by a statistically significant amount to a new constant level. In order to reliably demonstrate such an occurrence, the detection threshold in a region must be constant with time. If the detection capability is improved with time (a condition which one hopes exists in many parts of the world) a possible quiescence could be masked by increased reporting of small events. If, contrary to general hopes, the detection capability decreases with time an artificial "quiescence" may be produced.

The straightforward way to deal with this problem is to use only earthquakes of magnitude larger than the minimum magnitude for which the data set is complete (all events located) for all time considered. However, this procedure usually leads to elimination of 30 to $70 \%$ of the data. In most seismically active areas such a reduction results in data sets containing such small numbers of events, that statistical statements regarding changes of seismicity rate are not possible.

Because of this problem, we studied the number of earthquakes reported per year for the whole earth, as well as for tectonic regions broken down into magnitude bands. Our main results are the following:

(1) The world seismicity catalogue contains much fewer events for the years before 1963 than after that time. We therefore use post 1962 data only, 
unless detailed local catalogues exist.

(2) The world seismicity catalogue contains constant ( \pm small variance) annual rates of earthquakes with $\mathrm{m} \geqq 4.5$ for the years 1963 through 1979. This constancy is also observed for most tectonic regions examined.

(3) The NOAA Hypocenter Data File contains two major decreases in detection capability. The first occurred in the Western Hemisphere during 1968. At this time the rate of reporting of events with $\mathrm{mb}<4.5$ decreased by $40 \%$ in the Western Hemisphere while the rate of reporting of events with $\mathrm{mb} \geqq 4.5$ remained constant. A second decrease of about $50 \%$ in the rate of reporting of small events ( $\mathrm{mb}<4.5$ ) occurred during 1976 . This decrease occurred in most of the Northern Hemisphere. In some regions the rate of reporting of small events recovered during early 1978.

The 1968 decrease seems to have been due to the closure of the VELA array stations (TFO, UBO, BMO, CPO, WMO). The cause of the 1976 detection capability decrease is unknown.

The details of our findings will be described in a manuscript which will be submitted for publication shortly. The abstract of this paper is contained in Appendix C.

4. Seismicity quiescence within source volumes of recent large earthquakes

The study of seismicity patterns in and around the source volumes of past large earthquakes was designed to detect seismicity precursors if they exist. We found that seismicity quiescence (usually about $50 \%$ reduction in rate) occurs before many large ruptures.

Some general results are: 
(1) For earthquakes with $M_{s} \leqq 7.0(L \leqq 100 \mathrm{~km})$ the world seismicity catalogue does not contain enough data to allow reliable resolution of precursory rate changes for most tectonic areas. $\div$

(2) For most plate boundary segments of length $\geqq 100 \mathrm{~km}$ the seismicity rate remains constant ( \pm small variances) over many years, even decades.

(3) Seismicity rates of neighboring plate boundary segments can be closely the same over many years.

(4) In source volumes of some large earthquakes no seismicity rate changes could be detected during many years before the events.

(5) In source volumes of some large earthquakes $\left(6.5 \leqq \mathrm{M}_{s} \leqq 8.0\right)$ clear decreases of seismicity rate could be demonstrated to have lasted for years before the respective main shocks.

Appendix $B$ contains the abstract of a manuscript describing seismicity rates in the source volumes of recent gapfilling earthquakes.

\section{Is seismicity quiescence a precursory phenomenon?}

It is difficult to prove that a given phenomenon represents a precursor to an earthquake. However, several facts suggest that quiescence is a precursory phenomenon: (1) Most instances of quiescence anomalies defined by us are unique within space (the plate boundary in question) and time (1963-1979) and they occur before large main-shocks or up to the present time. A few of the anomalies lasting less than 2 years are not unique. However, there sometimes exist false alarms (comparable anomalous periods without main-shocks terminating them) along the same plate boundary. (2) The observed anomalies are closely linked to the main-rupture volumes both in space and time. (3) In one case (Hawaii) two independent other precursory changes occurred during 
approximately the same time, and in the same crustal volume as did the seismicity anomaly. (For detailed arguments see various papers listed in Chapter C).

\section{Model for quiescence.}

$$
=
$$

4. It appears that quiescence is often developed in some parts of the ultimate rupture volume, while the remaining parts show no seismicity rate decrease. This observation together with the geodetic evidence suggesting precursory strain relaxation (in the case of the Hawaii earthquake) is the basis for our "hard-asperities within a strain-softening fault plane" model. We suggest that precursory creep displacement on part of the fault plane relaxes the crustal volume surrounding these strain softening fault segments, resulting in drastically reduced earthquake rates there. Hard asperities on the fault surface remain stuck and continue to be stress loaded. Therefore they continue to produce small earthquakes at a constant or increased rate up to the main-rupture initiation, which will occur in one of these major asperities. (For details see our article on the Kalapana 1975 earthquake.)

\section{Quiescence within seismic gaps}

Strong evidence was accumulated, on a quantitative basis, that seismicity quiescence precedes some (not all) large earthquakes. Therefore we hypothesize that seismicity quiescence observed to last to the present is a precursor to a future earthquake, with dimensions roughly equal to the quiet area, but not larger than the largest known event in the tectonic region in question.

We have examined the seismicity rate along the Hellenic island arc where we also defined seismic gaps. We found that several segments of seismic gaps are in a state of quiescence now. That is, several years before the present, the seismicity rate dropped by at least $40 \%$ and the change is highly significant (according to normal deviate or t-tests). According to our hypothesis large rup- 
tures are expected to occur along these plate boundary segments (see Appendix A).

\section{ARTICLES PREPARED}

The following articles were produced with support of this contract:

1. Seismic quiescence in the Western Hellenic arc suggests large earthquakes are in preparation, Nature, 289, 785-787, 1981.

2. Earthquake hazard in the Hellenic arc, Ewing Symposium on Earthquake Prediction, Proceedings, in press, accepted for publication.

3. Precursory seismicity patterns: Stalking the mature seismic gap. Ewing Symposium on Earthquake Prediction, in press, accepted for publication.

4. Precursory seismicity quiescence in the New Hebrides arc, Bull. Seism. Soc. Amer., submitted.

5. Seismicity rates in the Central Aleutians: A quantitative study of precursors to moderate earthquakes, J. Geophys. Res., submitted.

\section{CONCLUSIONS AND RECOMMENDATIONS}

The world seismicity catalogue contains enough data to allow statistically meaningful seismicity rate studies for some plate boundaries, but not for others. All strike-slip boundaries seem to have too low a seismicity rate for study by the world seismicity catalogue.

The reporting quality of small events $(m<4.5)$ varies with time. The year 1963 marked a strong reporting increase. Surprisingly, decreases occurred in 1968 and 1976 which affected large parts of the globe.

The seismicity rate in $100 \mathrm{~km}$ plate boundary segments is constant enough (small variance) in most areas to allow reasonable definitions of the background rate. This is no longer true when main-shocks occur within or near the volume 
in question during the background period.

The seismicity rate was demonstrated to have decreased by $40 \%$ to $90 \%$ before some large earthquakes. These changes were usually confined to the

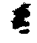
source volumes, and they were judged to be highly significant based on the normal deviate (z) test. Out of 34 main-shocks selected, 11 could not be studied because the earthquake rate in the source volume was too low for meaningful analysis.

Periods of quiescence not followed by main shocks, but exhibiting rate decreases and durations equal to or larger than some precursory anomalies, were termed "false alarms". False alarms were found for periods of less than 24 months to several years.

We propose that the cause of quiescence is a decrease of the tectonic stress in parts of the main-shock source volume, due to fault creep (strain softening). This model is based on the geodetically observed strain relaxation before the Hawaii earthquake, and it agrees with models based on rock mechanics laboratory observations.

Two potentially disastrous earthquakes are predicted for the Hellenic island arc. Among the areas of present quiescence these are located in the most populous region. The tectonic events in the Hellenic island arc should therefore receive special attention. We strongly recommend that the Hellenic arc be instrumented for detailed monitoring of the seismicity and crustal movements there, with the main purpose of detecting foreshocks and precursory crustal deformations, so that our long term prediction could be sharpened in space and time. 


\section{Seismic quiescence in the Western Hellenic Arc may foreshadow large earthquakes}

\author{
M. Wyss
}

CIRES, University of Colorado, Boulder, Colorado 80309, USA

\section{Baer}

Institute of Geophysics, ETH-Hoenggerberg, CH-8093 Zürich, Switzerland

South of Crete, the seismicity rate was constant in space and time between 1950 and 1978, but in the Western Hellenic Trench the rate was the same as that south of Crete until 1962, whereupon it decreased by $80 \%$. We now suggest that the anomaly constitutes a warning of large earthquakes within the coming decade.

Studies $^{1.2}$ of the events preceding 20 earthquakes of magnitude greater than 6.0 have shown decreases of about $50 \%$ in the frequency of small earthquakes for several years before the main shocks. This was for example the case in the years preceding a Hawaiian earthquake of magnitude 7.2 , where the decrease in seismicity was accompanied by two other precursor phenomena-relaxation of crustal strain and a change of seismic velocity $^{3}$. Our hypothesis is therefore that a significant decrease of seismicity rate within a given volume is a sign that preparations have begun for one or more major earthquakes within that volume.

The region surrounding the Aegean Sea has the highest seismicity rate in western Eurasia ${ }^{4}$, and its tectonic complexity has been widely discussed ${ }^{5-11}$. There is general agreement that the Hellenic trench-island arc system is a clear tectonic unit, that subduction occurs along it and that it can be regarded as a plate boundary. The direction of convergence is roughly perpendicular to the Western Hellenic Arc and approximately parallel to its eastern segment ${ }^{\circ}$. The rate of convergence may increase from west to east and is estimated to be between 2.5 and $7 \mathrm{~cm} \mathrm{yr}^{-1}$ (ref. 6). Assuming that no substantial aseismic creep occurs, these consumption rates imply that enough strain energy has been stored here during loading cycles of the order of $100-$ $200 \mathrm{yr}$ to produce large earthquakes.

The time of the last very large ruptures along the Hellenic plate boundary is a matter of debate. Eight earthquakes of magnitude $\geqslant 7.75$ occurred in this area between 1805 and 1926 , but most authors consider that these events occurred at depths of $100 \mathrm{~km}$ and locations about $100 \mathrm{~km}$ north of the plate boundary ${ }^{12}$. By this interpretation the plate boundary has not been ruptured in great events for about $200 \mathrm{yr}$, which would imply that 5-15 m of potential displacement have been stored. However, we propose the data on the destruction ${ }^{18}$ caused by these large earthquakes to mean that these events were shallow ruptures of the plate boundary ${ }^{20}$. According to our interpretation, all the Hellenic plate boundary, except a $150-\mathrm{km}$ segment west of Crete, was ruptured between 1805 and 1926. We therefore estimate the potential earthquake slip stored at present to be $\sim 2.5-6 \mathrm{~m}$ (depending on the location along the arc). We conclude that, according to either interpretation, the Hellenic arc could reasonably be expected to be capable of very large earthquakes at the present time.

To determine whether any part of the arc is in a preparatory stage to rupture we studied the rate of occurrence of shallow earthquakes (0-100 km depth) as a function of space and time. A complete, pooled ${ }^{13-15}$ data set for earthquakes of $>4.9$ mag was obtained for the period 1950-78. Analysis of cumulative numbers of earthquakes as a function of time showed that their overall rate of incidence in the Hellenic Arc decreased slightly after 1962 . To determine the portion of the plate boundary responsible for this change we examined seismicity rates within 12 random overlapping volumes, defined in Fig. 1. Three facts became evident: (1) The seismicity rates in the neighbouring volumes $5,6,7$ and 8 were the same to within $10 \%$; they were approximately constant over the 28 -yr period; and they were relatively high ( 1.5 events $\left.\mathrm{yr}^{-1}\right)$ for this island arc. (2) Volumes $1-3$ showed a common pattern of high rates $\left(\sim 1.5\right.$ events $\left.\mathrm{yr}^{-1}\right)$ for the first $12 \mathrm{yr}$ followed by a much lower rate $\left(0.5\right.$ events $\left.\mathrm{yr}^{-1}\right)$ during the remainder of the period. (3) A mixture of rates and patterns existed in volumes 9-12. Based on these observations, subvolumes of the arc with similar patterns were merged for further study of the seismicity rates.

Figure 2 shows the cumulative numbers of earthquakes as a function of time for the super-volumes designated I, II and III in Fig. 1 which are of similar dimensions (Fig. 2). The seismicity rate in these three volumes was the same up to the early 1960 s, after which time volume II continued to produce earthquakes at the same rate as before, while volume I showed a highly significant decrease of seismicity to about $20 \%$ of its previous rate. We interpret this decrease of seismicity to be an anomaly precursory to one or several large earthquakes in volume $I$. The data of volume III are less clear, but an anomaly may have existed there since about 1970 . We conclude that the greatest likelihood of very large earthquakes exists in the western part of the Hellenic Trench.

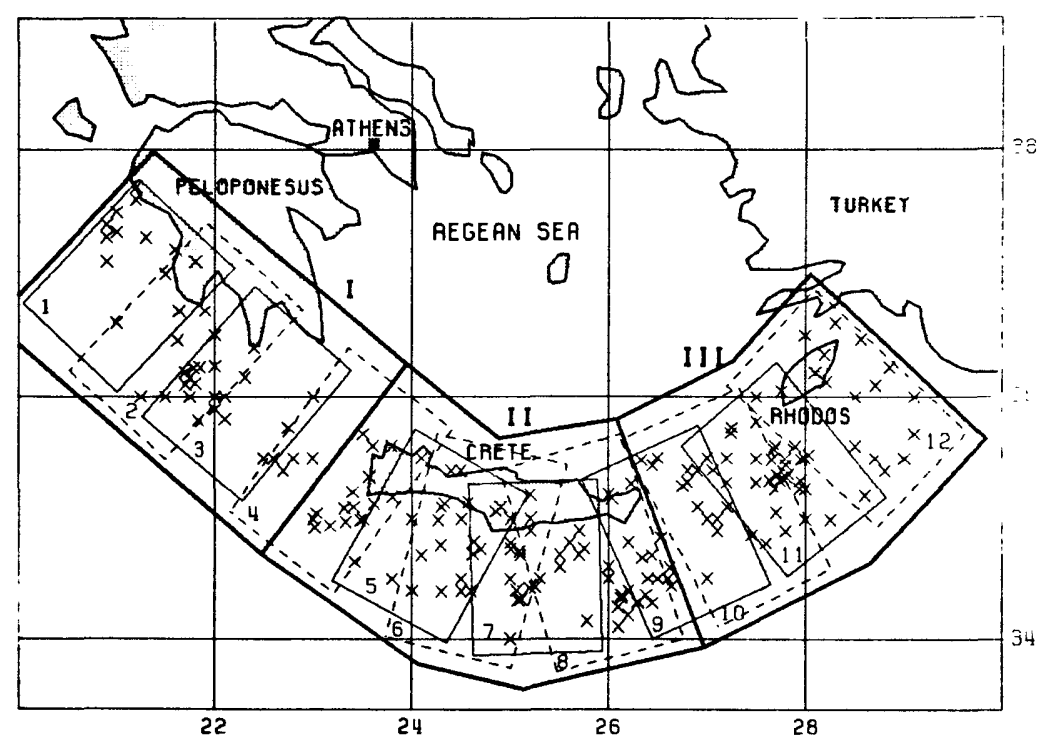

Fig. 1 Epicentre map of all earthquakes used (1950-78, $5.0 \mathrm{mag}, 0 \leqslant$ depth $\leqslant 100 \mathrm{~km}$ ) in the seismicity study of the Hellenic arc. Subvolumes for which seismicity rates as a function of time were determined separately are labelled 1-12. Large segments of the arc for which cumulative seismicity is shown as a function of time in Fig. 2 are labelled I, II and III. 


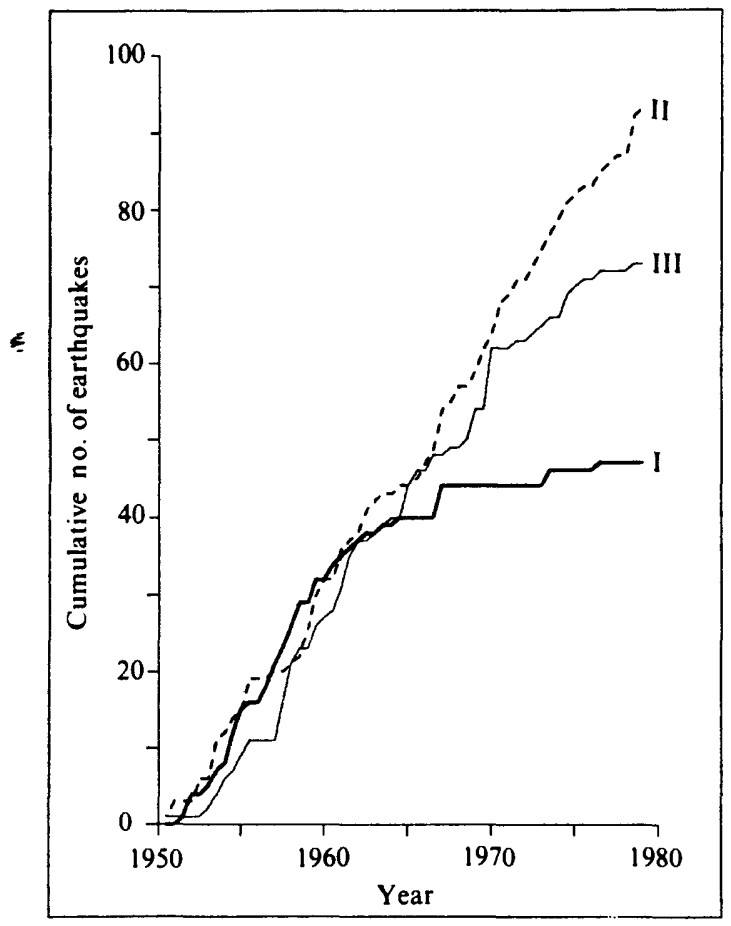

Fig. 2 Cumulative number of earthquakes ( $\geqslant 5.0 \mathrm{mag}$ ) as a function of time for the three large segments I, II and III of the Hellenic arc (defined in Fig. 1). As the seismicity in volume III is dominated by swarms (steps in the curve), we can reach no conclusion for this region. Note that the seismicity rates in I and II are closely similar up to 1962 , after which time the rate in volume I is reduced to $20 \%$ of this rate while the rate in II continues at the pre-1962 level. The establishment of the World Wide Standard Seismograph network did not affect seismicity resolution in the area because the location capability is mostly based on European stations.

The largest length of the arc segment which may be ready for rupturing is approximately $400 \mathrm{~km}$ (volume I and immediately adjoining volumes containing high seismicity). Based on the destruction caused by the great earthquakes which occurred in the Western Hellenic Trench during the nineteenth and early twentieth centuries ${ }^{18}$, we estimate the most likely length of future ruptures to be about $100 \mathrm{~km}$. Using the hypothesis that the seismicity anomaly in the Western Hellenic Trench represents a precursor, and assuming that the precursor time is correlated with anomaly dimension, we expect that the sequence of large earthquakes will start between 1980 and 1991. Using seismicity data alone, we cannot estimate the time of occurrence more accurately than this because of the scatter in the data defining the anomaly dimension versus precursor time relation ${ }^{1}$.

We expect an earthquake with the following source parameters to rupture the Hellenic arc plate boundary: location, near $23.5^{\circ} \mathrm{E}$; size, lengths $=100 \pm 50 \mathrm{~km}$, magnitude $7.75 \pm 0.5$; occurrence, $1980 \leqslant T_{0} \leqslant 1991$.

Although precursor seismicity patterns cannot be identified with certainty along the other segments of the Hellenic Trench, it seems reasonable to expect large earthquakes there also. However, this prediction should not be made without emphasizing the rudimentary nature of our understanding of the processes which lead to earthquakes. Even though the number of well documented seismicity quiescence precursors is increasing, we do not know whether it is possible for seismicity quiescence anomalies to be terminated without a main shock.

Nevertheless, we believe that precautionary measures are warranted, although we are aware of the possible negative effects of broadcasting an earthquake prediction ${ }^{19}$. Ohtake et $a_{l}{ }^{16}$, about 2 yr before the $7.8 \mathrm{mag}$ Oaxaca earthquake in 1978 , showed that quiescence had begun in the Oaxaca gap in mid1973, but their report produced no constructive action and was, in fact, ultimately detrimental to the area concerned. We hope that previous mistakes will not be repeated in the case of the Hellenic Trench and that scientific surveillance of the area will be started.

This research was supported by funds of the Institute for Geophysics, ETH-Zürich, and by US Geological Survey contract no. 14-08-001-18386.

Received 14 October; accepted 2 December 1980

Wyss, M. \& Habermann, R. E. Pure appl. Geophys. 117, 1195 (1979)

2. Habermann, R. E. 3rd Maurice Ewing Symp. Abstr. (1980).

3. Wyss, M., Klein, F. W. \& Johnston, A. C. Nature 289, 231-234 (1981),

4. Barazangi, M. \& Dorman, J. Bull. seism. Soc. Am. 59, 369 (1969).

5. McKenzie. D. P. Nature 226, 239 (1970); Geophys. J. R. astr. Soc. 55, 217 (1978).

6. Le Pinchon, X. \& Angelier, J. Tectonophysics 60, 1 (1979).

7. Papazachos, B. C. \& Delibasis, N. D. Tectonophysics 7, 321 (1969).

8. Papazachos, B. C. \& Delibasis, N. D. Tecionophysics 7, 321 (1969).

9. Papazachos, B. C. Geophys. J. R. astr. Soc. 33, 421 (1973)

10. Comninakis, P. E. \& Papazachos, B. C. Bull. geol. Soc. A m. 83, 1093 (1972).

11. Berckhemer, H. in Int. Symp. Structural History of the Mediterranean Basins leds EejuDuval, B. \& Montadert, L.) 303 (Editions Technip, Paris, 1977).

12. Galanopoulos, A. Ann. Geofis. 20, 109 (1967).

13. Comninakis P. E. \& Papazachos, B. C. A Catalogue of Earthquakes in the Mediterranean and Surrounding Area for the Period 1901-1975 (Geophysical Laboratory, University of Thessaloniki, 1978).

14. Drakopoulos, J. et al. Bull, natn. Obs. Athens, Seism. Inst. (1978)

15. World Hypocenter Data File (NOAA, Washington DC, 1979 ).

6. Ohtake, M., Matumoto, T. \& Latham, G. V. Pure appl. Geophys. 115, $375(1977)$

17. Galanopoulos, A. Ann. Geofis. 20, 109 (1967).

18. Sieberg. A. Denkschr. med.-naturu: Ges. Jena 18, 2nd edn

19. Garza, T. \& Lomnitz, C. Pure appl. Geophys. 117, 1187 (1979).

20. Wyss, M. \& Baer, M. 3 rd Maurice Ewing Symp. Abstr. (1980). 


\title{
APPENDIX B: PRECURSORY SEISMICITY PATTERNS: \\ STALKING THE MATURE SEISMIC GAP
}

\section{R.E. Habermann $\quad \because=$}

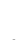

\begin{abstract}
Mature seismic gaps are defined here as gaps in which a possible precursor to a future event has been identified. The seismic potential of these seismic gaps is enhanced relative to immature seismic gaps. The seismic gap hypothesis by itself provides an excellent means of narrowing spatial limits along plate boundaries within which the great earthquakes of the next several decades are expected. To narrow the temporal limits on these forecast events, identified gaps must be monitored for signs of maturity. Decreased seismicity rates (number of events reported/unit time) have been reported before over fifty large earthquakes. Seismicity rates measured teleseismically are tested as a possible indicator of maturity by examining data from the NOAA HDF in the regions of eleven recent large events. These events were chosen as test cases because they occurred in previously recognized seismic gaps.
\end{abstract}

Many previous seismicity studies lack quantitative evaluation of patterns or changes of patterns which are proposed as precursors. This makes many of the results unconvincing. In this work seismicity data is quantified by studying seismicity rates, the number of events per month. Changes in rates are evaluated using the normal deviate $(z)$ test for a difference between two means. Several techniques for appling this test to seismicity data are proposed. These techniques offer various approaches to quantitatively defining seismicity rate changes and evaluating their temporal and spatial uniqueness. 
Two of the eleven events examined (Sitka, 1972 and St. Elias,1978) occurred in regions for which the teleseismic seismicity was too sparse to allow study of seismicity rates. Rates preceding two events in the Hokkaido corner, the South Kuriles 1969 and Nemuro-oki 1973 earthquakes, could not be evaluated because of the complex seismicity of the region. Of the remaining seven events, the Tokachi-oki 1968, Colima 1973, and the Oaxaca 1978 earthquakes were preceded by temporally and spatially unique seismic quiescence. The Kamchatka 1971 event was preceded by a precursory cluster of events. The Lima 1974 and Solomon Islands 1978 events were preceded by clusters which may reflect similar phenomena but neither case was as clearr as the Kamchatka 1971 case. Only the Guerrero 1979 event was not preceded by a recognizable seismicity anomaly.

The multiple asperity model for earthquake precursors predicts that two types of precursors will be observed in upcoming rupture zones. High-stress precursors (dilatancy related velocity anomalies and increased seismicity) occur in locked portions of the upcoming rupture (asperities). Seismic quiescence occurs in regions of the rupture zone which experience precursory displacement and decreased stresses. The ratio between locked and unlocked areas of the future rupture $(R l)$ may be important in determining what type of seismicity precursors will occur. Possible differences in $R l$ for different ruptures offers a speculative explanation for the occurrence of different types of precursory anomalies. 


\section{APPENDIX C: CONSISTENCY OF TEILESEISMC REPORTING SINCE 1963}

\section{R.E. Habermann}

(-

\section{Abstract}

Changes in the rate of occurrence of smaller events have been recognized in the rupture zones of upcoming large earthquakes in several post-earthquake and one pre-earthquake study. A data set in which a constant portion of the events in any magnitude band are consistently reported through time is crucial for the recognition of seismicity rate changes which are real (related to some process change in the earth). Such a data set is termed a homogeneous data set.

The consistency of reporting of earthquakes in the NOAA Hypocenter Data File (HDF) since 1963 is evaluated by examining the cumulative number of events reported as a function of time for the entire world in eight magnitude bands. It is assumed that the rate of occurrence of events in the entire world is roughly constant on the time scale examined here because of the large size of the world-wide earthquake production system.

The rate of reporting of events with magnitudes above $m_{b}=4.5$ has been constant or increasing since 1963. Significant decreases in the number of events reported per month in the magnitude bands below $m_{b}=4.5$ occurred during 1968 and 1976. These decreases are interpreted as indications of decreases in detection capability because they occur at times of constant rates of reporting of larger events, and because similar decreases have been described in the teleseismic data reported by the International Seismological Center. 
During 1968 the detection decreased in the United States, Central and South America and portions of the South Pacific. This decrease is probably due to the closure of the VELA arrays, BMO, TFO, CPQ . UBO, and WMO. During 1976 the detection decreased in most of the seismically active regions of the western hemisphere, as well as in the region between Kamchatka and Guam. The cause of this detection decrease is unclear.

These detection decreases seriously affect the amount of homogeneous background period available for the study of teleseismic seismicity rate changes. If events below the minimum magnitude of homogeneity are eliminated from the teleseismic data sets, the resulting small numbers of events render many regions unsuitable for study. Many authors have reported seismicity rate decreases as possible precursors to great earthquakes. Few of these studies have considered detection decreases as possible explanations for the results. This analysis indicates that such considerations can not be avoided in studies of teleseismic data. 